\title{
PENERAPAN ECODRAINAGE MELALUI BIOPORI DI JALAN DUKUH KUPANG SURABAYA
}

\author{
Faradlillah Saves \\ Dosen Prodi Sipil, Fak. Teknik, Universitas 17 Agustus 1945 Surabaya \\ e-mail: farasaves@untag-sby.ac.id
}

\begin{abstract}
ABSTRAK
Jalan Raya Dukuh Kupang Barat, Kota Surabaya merupakan salah satu daerah yang padat penduduk. Hal ini tentu berpengaruh pada berkurangnya ruang terbuka hijau sehingga menyebabkan banjir. Dalam penelitian ini peneliti mencoba menerapkan sistem ecodrainage melalui pembuatan resapan biopori di lokasi penelitian untuk menanggulangi permasalahan tersebut. Tahap awal adalah survey lapangan guna mendapatkan informasi faktual terkait banjir setempat. Langkah selanjutnya melakukan analisis hidrologi dan hidrolika. Kemudian penerapan sistem ecodrainage melalui resapan biopori dengan membuat percobaan terkait laju infiltrasi di lokasi penelitian yang tidak dapat menampung debit air serta melakukan analisis Lubang Resapan Biopori (LRB). Berdasarkan hasil penelitian terdapat 2 saluran eksisting yang memiliki debit lebih besar daripada kapasitas saluran. Sehingga debit banjir tidak dapat tertampung, yaitu terdapat pada saluran ke 2 dan saluran ke 3. Untuk menanggulangi banjir tersebut perlu diterapkan system ecodrainage berupa 3107 buah LRB pada saluran ke 2 dan 1273 buah LRB pada saluran ke 3.
\end{abstract}

Kata kunci : Banjir, Ecodrainage, Resapan biopori

\begin{abstract}
Dukuh Kupang Barat, Surabaya is one of the most densely populated areas. This certainly has an effect on reducing green open space, causing flooding. In this study, the researchers tried to apply the ecodrainage system by making biopore infiltration on study area to overcome this problem. The initial stage is a field survey to obtain factual information regarding local flooding. The next step is to perform hydrological and hydraulics analysis. Then the application of the ecodrainage system through biopore infiltration by making experiments related to the infiltration rate at the research location which cannot accommodate the water discharge and conducting a Biopore Infiltration Hole (LRB) analysis. Based on the research results, there are 2 existing channels that have a discharge greater than the channel capacity. So that the flood discharge cannot be accommodated, which is in the 2nd channel and the 3rd channel.To cope with the flood, it is necessary to apply an ecodrainage system in the form of 3107 LRBs on the 2nd channel and 1273 LRBs on the 3rd channel.
\end{abstract}

Keywords : Floods, Ecodrainage, Biopori Infiltration 


\section{PENDAHULUAN}

Sistem jalan di suatu kawasan, perkotaan, kota maupun antar provinsi berkembang cukup pesaat. Hal ini tentu seiiring dengan perkembangan jaman dan teknologi. Sehingga kondisi jalan tentu menjadi hal yang sangat vital untuk keberlangsungan hidup manusia. Salah satu permasalahan yang sering terjadi di jalan adalah permasalahan banjir.

Area resapan air yang ada di lokasi penelitian yaitu di sekitar jalan Raya Raya Dukuh Kupang Barat, Kota Surabaya sudah mulai berkurang akibat padatnya pemukiman sehingga menimbulkan beberapa permasalahan air seperti banjir. Pada musim hujan terdapat beberapa saluran eksisting yang sudah tidak dapat menampung debit banjir yang ada, hal ini juga dipicu dengan kondisi eksisting saluran yang telah mengalami banyak kerusakan.

Berdasarkan hal tersebut maka diperlukan adanya evaluasi serta solusi dalam perencanaan sistem drainase di lokasi penelitian. Penerapan sistem ecodrainage merupakan salah satu inovasi yang dapat diaplikasikan pada lokasi studi melalui resapan biopori sehingga dapat menanggulangi banjir yang terjadi di masim hujan.

\section{TINJAUAN PUSTAKA}

\subsection{Analisis Hidrologi}

Analisis hidrologi adalah salah satu analisis yang sangat penting dalam perencanaan. Analisis hidrologi ini nantinya akan digunakan sebagai dasar dalam penentuan dimensi yang tepat dalam perencanaan sistem drainase sehingga saluran drainase dapat direncanakan secara efektif dan efisien. Tahapan dalam analisis hidrologi untuk mendapatkan debit antara lain: Pengumpulan data hidrologi, analisis frekuensi, analisis periode kala ulang, analisis intensitas dan waktu hujan, dan analisis debit rencana.

\subsection{Curah Hujan Maksimum}

Curah hujan maksimum bisa dihitung menggunakan 3 metode, yaitu metode rerata hitung, metode thiessen, dan metode isohyet. Dalam penelitian ini diambil metode rerata hitung hal ini didasarkan menurut Soemarto, C.D, 1995 metode rerat hitung dapat digunakan untuk daerah dengan beberapa stasiun hujan.

1. Metode Rerata Hitung

Untuk menghitung curah hujan maksimum dengan metode ini dapat dilakukan dengan cara menjumlahkan tinggi hujan dari seluruh stasiun kemudian dibagi dengan jumlah stasiun hujan. (Soemarto C.D, 1995) 


$$
\mathbf{R}=\frac{1}{n} \mathbf{X}\left(\mathbf{R}_{\mathrm{A}}+\mathbf{R}_{\mathrm{B}}+\mathbf{R}_{\mathrm{C}}+\ldots+\mathbf{R}_{\mathrm{n}}\right)
$$

Keterangan :

$\mathrm{R}$

: Tinggi curah hujan rerata

$\mathrm{R}_{\mathrm{A}}, \mathrm{R}_{\mathrm{B}}, \ldots, \mathrm{R}_{\mathrm{n}}$

$\mathrm{N}$

: Tinggi curah hujan stasiun hujan $A, B, \ldots, n$

: Banyaknya stasiun hujan

\subsection{Debit Banjir Rencana}

Perhitungan debit banjir rencana bertujuan untuk mengetahui debit yang terjadi berdasarkan data curah hujan yang ada. Hal tersebut menjadi dasar penting dalam perencanaan bangunan air seperti pada perencanaan saluran drainase. Dengan adanya debit banjir rencana, maka dapat ditentukan dimensi saluran yang sesuai untuk menampung kapasitas yang ada. Dalam penelitian ini metode Rasional digunakan untuk menghitung debit banjir rencana

$$
Q=0,278 \cdot C \cdot I \cdot A
$$

Keterangan:

Q : Debit maksimum ( $\left.\mathrm{m}^{3} / \mathrm{det}\right)$

C : koefisien limpasan

I : Intensitas hujan ( $\mathrm{mm} / \mathrm{jam})$

A : Luas daerah aliran $(\mathrm{km})$

\subsection{Analisis Hidrolika}

Analisis hidrolika dilakukan untuk mendapatkan kapasitas tampungan saluran sesuai dengan kondisi eksisting saluran.

$$
\mathbf{Q}=\underline{\underline{\mathbf{V}}} \mathbf{A}
$$

Keterangan:

$\mathrm{Q}=$ Debit hidrolika $\left(\mathrm{m}^{3} / \mathrm{det}\right)$

$A=$ Luas penampang saluran $\left(\mathrm{m}^{2}\right)$

$\mathrm{V}=$ Kecepatan aliran $(\mathrm{m} / \mathrm{dt})$

\subsection{Drainase Berwawasan Lingkungan (ecodrainage)}

Drainase berwawasan lingkungan merupakan pengelolaan air yang tidak menimbulkan dampak negative yang besar untuk lingkungan di sekitarnya. Sehingga ecodrainage ini bertujuan untuk melakukan treatment terhadap kelebihan air dengan cara meresapkan air secara alami dengan maksimal ke dalam tanah. 
Sistem ecodrainage dapat menjadi solusi yang efektif dalam menanggulangi pemasalahan air apabila mempertimbangkan beberapa factor dan dengan perencanaan yang matang. Menurut Sunjoto (2006), faktor tersebut antara lain adalah genangan, daerah tangkapan hujan, aspek hidrologi, tata guna lahan, demografi, topografi, social ekonomi, biaya, dll.

Beberapa metode drainase berwawasan lingkungan yang dapat digunakan di Indonesia adalah metode sumur resapan, metode lubang resapan biopori, metode kolam koservasi, metode side river polder dan metode penampung air hujan.

\subsection{Lubang Resapan Biopori}

Lubang resapan biopori (LRB) merupakan lubang silindris dengan kedalaman tidak lebih dari muka air tanah dan sekitar $100 \mathrm{~cm}$ serta berdiameter $10-30 \mathrm{~cm}$. Pembentukan biopori dipengaruhi oleh sampah organic. (Jhon Herf, 2009)

Salah satu keunggulan dan manfaat LRB adalah daya resap air lebih meningkat. Dengan adanya LRB secara langsung tentu akan menambah kawasan meresapnya air. (Kamir, 2009)

\section{METODE PENELITIAN}

Jl. Raya Dukuh Kupang Barat Kelurahan Dukuh Kupang Kecamatan Dukuh Pakis merupakan lokasi penelitian di salah satu daerah di kota Surabaya barat. Titik penelitian merupakan saluran drainase yang terdapat pada jalan utama dengan panjang 1,43 km. Tahap awal penelitiah adalah melakukan survey lapangan untuk mengetahui titik lokasi banjir, selanjutnya adalah melakukan analisis hidrologi dengan menggunakan data curah hujan 10 tahun (2009-2018). Langkah berikutnya adalah melakukan analisis hidrolika berdasarkan kondisi ekstisting pada saluran drainase.

Berdasarkan dua analisis tersebut maka dapat dilakukan evaluasi saluran drainase dan kemudian menentukan penerapan system ecodrainage melalui resapan biopori. Sebelum melakukan analisis resapan biopori, perlu dilakukan tes laju infiltrasidengan alat single ring infiltrometer. Selanjutnya akan diperoleh presentase debit yang masuk ke dalam LRB, desain serta jumlah LRB yang di butuhkan untuk resapan biopori. Berikut merupakan bentuk diagram alir dalam penelitian ini ditunjukkan pada Gambar 1. 


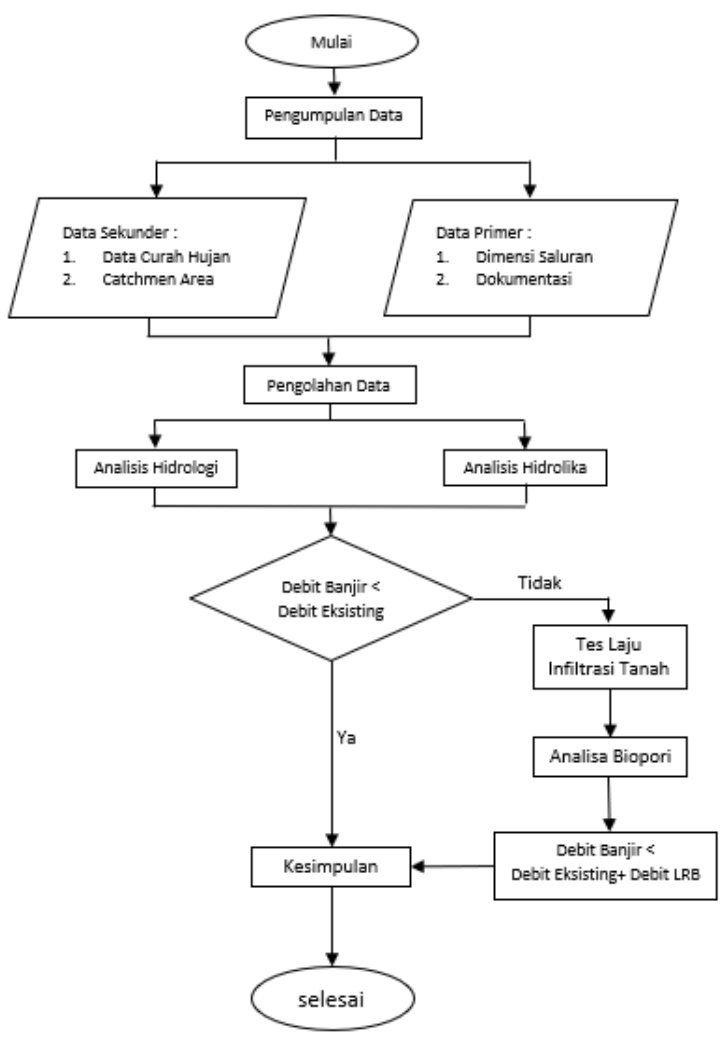

Gambar. 1

Diagram Alir Penelitian

Sumber: Hasil penelitian, 2021

PAWON: Jurnal Arsitektur, Nomor 02 Volume V, Juli-Desember Tahun 2021, ISSN 2597-7636 


\section{HASIL DAN PEMBAHASAN}

\subsection{Analisis Hidrologi}

Analisis hidrologi dilakukan dengan menghitung curah hujan maksimum, intensitas hujan, koefisien pengaliran, catchment area. Selanjutnya diperoleh debit banjir rencana.

\subsection{Analisis Curah Hujan Maksimum}

Pada lokasi penelitian terdapat 3 stasiun hujan yang berpengaruh. Sehingga data curah hujan diambil dari stasiun hujan kandangan, stasiun hujan gunung sari dan stasiun hujan simo.

Data curah hujan yang digunakan adalah dari tahun 2009 - 2018. Berdasarkan data tersebut maka dapat dilakukan analisis curah hujan maksimum menggunakan metode rerata hitung.Perhitungan ditunjukkan pada Tabel 1 berikut:

Tabel 1

Perhitungan Curah Hujan Harian Maksimum

\begin{tabular}{cccccc} 
No & Tahun & $\begin{array}{c}\text { Stasiun } \\
\text { Kandangan } \\
(\mathbf{m m})\end{array}$ & $\begin{array}{c}\text { Stasiun } \\
\text { Simo }(\mathbf{m m})\end{array}$ & $\begin{array}{c}\text { Stasiun } \\
\text { Gunungsari } \\
(\mathbf{m m})\end{array}$ & $\begin{array}{c}\text { Curah } \\
\text { Hujan Rata } \\
- \text { Rata } \\
\mathbf{R}(\mathbf{m m})\end{array}$ \\
\hline 1 & 2009 & 78 & 107 & 78 & 87.67 \\
\hline 2 & 2010 & 127 & 89 & 114 & 110.00 \\
\hline 3 & 2011 & 79 & 84 & 102 & 88.26 \\
\hline 4 & 2012 & 82 & 67 & 102 & 83.67 \\
\hline 5 & 2013 & 75 & - & 97 & 57.33 \\
\hline 6 & 2014 & 81 & 78 & 86 & 81.50 \\
\hline 7 & 2015 & 63 & 88 & 69 & 73.17 \\
\hline 8 & 2016 & 120 & 86 & 94 & 100.00 \\
\hline 9 & 2017 & 98 & 102 & 120 & 106.67 \\
\hline 10 & 2018 & - & 49 & 85 & 44.67 \\
\hline \multicolumn{2}{c}{ Jumlah } & 803 & 750 & 946 & 832.92 \\
\hline Rata - Rata & 80.3 & 74.98 & 94.6 & 83.29 \\
\hline
\end{tabular}

Sumber: Hasil Perhitungan, 2021

\subsection{Analisis Waktu Konsentrasi (tc)}

Besarnya nilai waktu konsentrasi dapat dianalisis menggunakan rumus berikut :

Kemiringan Rata-rata Sungai

$$
S=\frac{H}{0,9 \times L}
$$




$$
\begin{aligned}
& S=\frac{2.98-0.98}{0.9 \times 1035} \\
& S=0,002147
\end{aligned}
$$

Waktu Konsentrasi (tc)

$$
\begin{aligned}
t c & =\left(\frac{0,87 \times L^{2}}{1000 \times S}\right)^{0,385} \\
\underline{t c} & =\left(\frac{0.87 \times 1.035}{1000 \times 0.002147}\right)^{0.385} \\
\underline{t c} & =0,7252001 \mathrm{jam}
\end{aligned}
$$

\subsection{Analisis Intensitas Hujan (I)}

Analisis intensitas curah hujan dilakukan dengan periode ulang 10 tahun serta dengan waktu konsentrasi yang telah dianalisis yaitu sebesar 0,73 jam.

$$
\text { 1) } \begin{aligned}
I_{2} & =\frac{R_{24}}{24} \times\left[\frac{24}{t}\right]^{2 / 3} \\
I_{2} & =\frac{87.92}{24} \times\left(\frac{24}{0.73}\right)^{2 / 3} \\
& =38.21 \mathrm{~mm} / \mathrm{jam} \\
\text { 2) } I_{5} & =\frac{100.51}{24} \times\left(\frac{24}{0.73}\right)^{2 / 3} \\
& =43.68 \mathrm{~mm} / \mathrm{jam} \\
\text { 3) } I_{10} & =\frac{103.96}{24} \times\left(\frac{24}{0.73}\right)^{2 / 3} \\
& =45.18 \mathrm{~mm} / \mathrm{jam}
\end{aligned}
$$


Tabel 2.

Rekapitulasi Intensistas Curah Hujan

\begin{tabular}{crrr}
$\begin{array}{c}\text { Periode Ulang } \\
\text { T (Tahun) }\end{array}$ & R24 (mm/jam) & Tc (Jam) & I (mm/jam) \\
\hline 2 & 87.92 & 0.73 & 38.21 \\
\hline 5 & 100.51 & 0.73 & 43.68 \\
\hline 10 & 103.96 & 0.73 & 45.18 \\
\hline
\end{tabular}

Sumber : Hasil Perhitungan, 2021

\subsection{Analisis Catchment Area (Ca)}

Catchment area pada penelitian ini dibagi menjadi 2 area berdasarkan dari arah aliran air di lapangan. Luas catchment area pada area 1 adalah 10.01 Ha dan $5.40 \mathrm{Ha}$ untuk luas area pada catcment area 2.

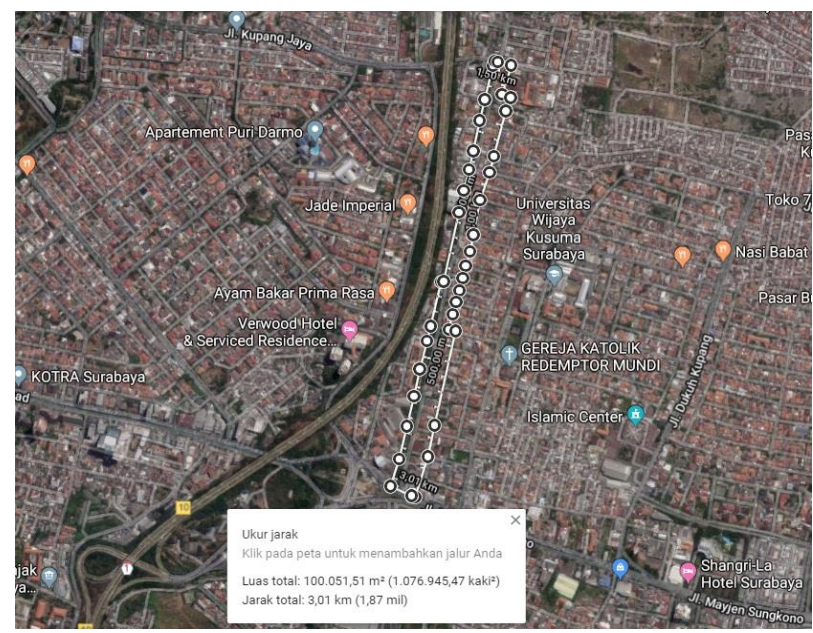

Gambar. 2

Catchment Area 1

Sumber: Hasil penelitian, 2021 


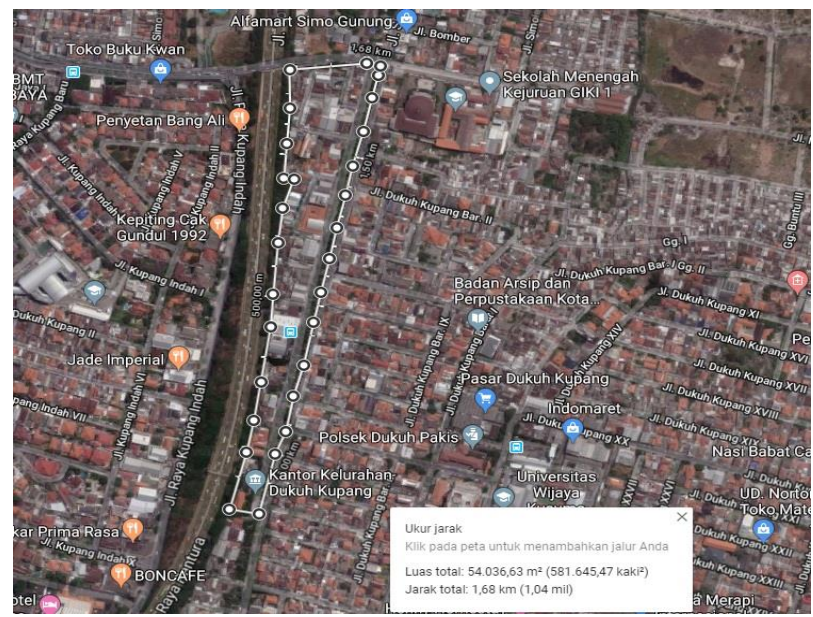

Gambar. 3

Catchment Area 2

Sumber: Hasil penelitian, 2021

\subsection{Analisis Debit Banjir Rencana}

Perhitungan ini dilakukan dengan mengidentifikasi koefisien pengaliran berdasarkan dengan tata guna lahan pada lokasi penelitian. Selain itu juga dipengaruhi oleh nilai intensitas curah hujan dan luar area. Berikut merupakan perhitungan koefisien pengaliran pada area 1 dan area 2 yang dapat ditunjukkan berikut:

Tabel 3.

Analisis Tata Guna Lahan Area 1

\begin{tabular}{ccccc}
\hline No & Komposisi & Deskripsi & Nilai C (Ci) & Luas Ai (Ha) \\
\hline 1 & Perumahan & Perkampungan & 0.4 & 6.96 \\
\hline 2 & Perkerasan & Jalan Aspal & 0.7 & 0.85 \\
\hline 3 & Hutan & Taman & 0.45 & 2.20 \\
\hline \multicolumn{3}{c}{ TOTAL } \\
\hline
\end{tabular}

Sumber : Hasil Perhitungan, 2021

Tabel 4.

Analisis Tata Guna Lahan Area 2

\begin{tabular}{ccccc}
\hline No & Komposisi & Deskripsi & Nilai C (Ci) & Luas Ai (Ha) \\
\hline 1 & Perumahan & Perkampungan & 0.4 & 3.94 \\
\hline 2 & Perkerasan & Jalan Aspal & 0.7 & 0.43 \\
\hline 3 & Hutan & Taman & 0.45 & 1.03 \\
\hline \multicolumn{5}{c}{ TOTAL } \\
\hline & Sumber : Hasil Perhitungan, 2021
\end{tabular}

PAWON: Jurnal Arsitektur, Nomor 02 Volume V, Juli-Desember Tahun 2021, ISSN 2597-7636 
Berikut merupakan contoh perhitungan debit rencana periode ulang 2 tahun pada area 1 , untuk perhitungan selanjutnya ditunjukkan pada rekapitulasi tabel 5 untuk area 1 dan tabel 6 untuk area 2.

\section{Kala ulang 2 tahun Area 1:}

$$
\begin{aligned}
& Q h_{2}=0,00278 \times C \times I \times A \\
& \begin{aligned}
Q h_{2} & =0.00278 \times 0.4363372 \times 38.21 \times 10.01 \\
& =0.46 \mathrm{~m}^{3} / \mathrm{det}
\end{aligned}
\end{aligned}
$$

Tabel 5.

Rekapitulasi Debit Banjir Rencana Catcment Area 1

\begin{tabular}{ccc} 
No & Periode Ulang & Debit \\
\hline 1 & 2 tahun & $0,46 \mathrm{~m}^{3} / \mathrm{dt}$ \\
\hline 2 & 5 tahun & $0,53 \mathrm{~m}^{3} / \mathrm{dt}$ \\
\hline 3 & 10 tahun & $0,55 \mathrm{~m}^{3} / \mathrm{dt}$ \\
\hline & Sumber : Hasil Perhitungan, 2021
\end{tabular}

Tabel 6.

Rekapitulasi Debit Banjir Rencana Catcment Area 2

\begin{tabular}{ccc}
\hline No & Periode Ulang & Debit \\
\hline 1 & 2 tahun & $0,25 \mathrm{~m}^{3} / \mathrm{dt}$ \\
\hline 2 & 5 tahun & $0,28 \mathrm{~m}^{3} / \mathrm{dt}$ \\
\hline 3 & 10 tahun & $0,29 \mathrm{~m}^{3} / \mathrm{dt}$ \\
\hline & Sumber : Hasil Perhitungan, 2021
\end{tabular}

\subsection{Analisis Hidrolika}

Saluran drainase pada lokasi peneltian berbentuk persegi dengan dimensi yang berbeda pada tiap saluran. Berikut merupakan hasil analisis hidrolika yang dilakukan pada 3 saluran di lokasi penelitian yang menunjukkan kapasitas tampungan pada masing-masing saluran.

Tabel 7

Rekapitulasi Analisis Hidrolika Saluran Eksisting

\begin{tabular}{cccccc}
$\begin{array}{c}\text { Tipe } \\
\text { Saluran }\end{array}$ & $\begin{array}{c}\text { Penampang } \\
\text { Basah } \\
(\mathbf{A})\end{array}$ & $\begin{array}{c}\text { Keliling } \\
\text { Basah } \\
(\mathbf{P})\end{array}$ & $\begin{array}{c}\text { Jari - Jari } \\
\text { Hidrolis } \\
\text { ( R) }\end{array}$ & $\begin{array}{c}\text { Kecepatan } \\
\text { Aliran } \\
\text { (v) }\end{array}$ & $\begin{array}{c}\text { Debit } \\
\text { Saluran } \\
\text { Existing } \\
\text { (Qs) }\end{array}$ \\
\hline Saluran 1 & 1 & 3.00 & 0.33 & 1.755 & 1.755 \\
\hline Saluran 2 & 0.35 & 1.95 & 0.20 & 1.235 & 0.413 \\
\hline Saluran 3 & 0.2 & 1.40 & 0.14 & 1.193 & 0.239 \\
\hline \multicolumn{5}{c}{ Sumber : Hasil Perhitungan 2021 }
\end{tabular}




\subsection{Evaluasi Saluran Drainase}

Berdasarkan analisis hidrologi dan hidrolika, didapat nilai Qhidrologi dan Qhidrolika Eksisting, sehingga apabila debit hidrologi > debit hidrolika maka saluran tersebut meluap/banjir, begitu juga sebaliknya. Berikut merupakan rekapitulasi evaluasi drainase ditunjukkan pada tabel 8.

Tabel 8

Evaluasi Saluran Drainase

\begin{tabular}{|c|c|c|c|c|}
\hline \multirow[t]{2}{*}{ Saluran } & \multicolumn{2}{|c|}{ Qhidrologi } & \multirow{2}{*}{$\begin{array}{l}\text { Qhidrolika } \\
\text { m³/det }^{3} /{ }^{2}\end{array}$} & \multirow{2}{*}{ Hasil Evaluasi } \\
\hline & $\begin{array}{l}\text { Periode } \\
\text { Ulang }\end{array}$ & $\mathrm{m}^{3} /$ det & & \\
\hline \multirow{3}{*}{ Saluran 1} & $\mathrm{Q}_{2}$ Tahun & 0.4637 & 1.754657416 & Memenuhi \\
\hline & $Q_{5}$ Tahun & 0.5301 & 1.754657416 & Memenuhi \\
\hline & $Q_{10}$ Tahun & 0.5483 & 1.754657416 & Memenuhi \\
\hline \multirow{3}{*}{ Saluran 2} & $\mathrm{Q}_{2}$ Tahun & 0.4637 & 0.412754958 & Meluap/Banjir \\
\hline & $\mathrm{Q}_{5}$ Tahun & 0.5301 & 0.412754958 & Meluap/Banjir \\
\hline & $Q_{10}$ Tahun & 0.5483 & 0.412754958 & Meluap/Banjir \\
\hline \multirow{3}{*}{ Saluran 3} & $\mathrm{Q}_{2}$ Tahun & 0.2487823 & 0.238662187 & Meluap/Banjir \\
\hline & $Q_{5}$ Tahun & 0.2843964 & 0.238662187 & Meluap/Banjir \\
\hline & $Q_{10}$ Tahun & 0.2941609 & 0.238662187 & Meluap/Banjir \\
\hline
\end{tabular}

Berdasarkan dari tabel 8, dapat disimpulkan bahwa terdapat 2 saluran eksisting yaitu pada saluran 2 dan saluran 3 yang tidak dapat menampung debit banjir rencana hingga periode ulang 10 Tahun.

\subsection{Analisis Ecodrainage (Drainase Berwawasan Lingkungan)}

Lubang Resapan Biopori merupakan salah satu alternatif dalam penanggulangan banjir dengan konsep berwawasan lingkungan. Sebelum merencanakan LRB perlu dilakukan analisis laju infiltrasi. Analisis laju infiltrasi di lokasi penelitian menggunakan:

Single Ring Infiltrometer

$\varnothing=25 \mathrm{~cm}$

$\mathrm{T}=25 \mathrm{~cm}$

Penelitian dilakukan di 6 titik berbeda. 3 titik dengan LRB dan 3 titik tanpa LRB, selanjutnya akan di analisis dengan menggunakan Infiltrasi Metode Horton. Analisis laju infiltrasi dengan LRB maupun tanpa LRB ditunjukkan berikut ini. 
Tabel 9

Perhitungan Laju Infiltrasi Dengan LRB

\begin{tabular}{cccc}
\hline \multirow{2}{*}{ No } & \multicolumn{3}{c}{ Dengan LRB } \\
\cline { 2 - 4 } & $\Delta \mathrm{t}$ & $\begin{array}{c}\text { Penurunan } \\
\text { (menit) }\end{array}$ & Laju Infiltrasi \\
\hline 1 & 5 & 13.4 & (cm/jam) \\
\hline 2 & 5 & 12.4 & 160.8 \\
\hline 3 & 5 & 11.4 & 148.8 \\
\hline 4 & 5 & 10.5 & 136.8 \\
\hline 5 & 5 & 9.4 & 112.8 \\
\hline 6 & 5 & 8.2 & 98.4 \\
\hline 7 & 5 & 6.9 & 82.8 \\
\hline 8 & 5 & 5.5 & 66 \\
\hline 9 & 5 & 5.1 & 61.2 \\
\hline 10 & 5 & 4.6 & 55.2 \\
\hline 11 & 5 & 3.9 & 46.8 \\
\hline 12 & 5 & 2.9 & 34.8 \\
\hline 13 & 5 & 2.9 & 34.8 \\
\hline 14 & 5 & 2.9 & 34.8 \\
\hline & Sumber : Hasil Perhitungan 2021 \\
\hline
\end{tabular}

Tabel 10

Perhitungan Laju Infiltrasi Tanpa LRB

\begin{tabular}{cccc}
\hline \multirow{2}{*}{ No } & \multicolumn{3}{c}{ Tanpa LRB } \\
\cline { 2 - 4 } & $\begin{array}{c}\Delta t \\
\text { (menit) }\end{array}$ & $\begin{array}{c}\text { Penurunan } \\
\text { (cm) }\end{array}$ & $\begin{array}{c}\text { Laju Infiltrasi } \\
\text { (cm/jam) }\end{array}$ \\
\hline 1 & 5 & 4.3 & 51.6 \\
\hline 2 & 5 & 3.75 & 45 \\
\hline 3 & 5 & 2.9 & 34.8 \\
\hline 4 & 5 & 2.7 & 32.4 \\
\hline 5 & 5 & 2.1 & 25.2 \\
\hline 6 & 5 & 1.8 & 21.6 \\
\hline 7 & 5 & 1.4 & 16.8 \\
\hline 8 & 5 & 1.25 & 15 \\
\hline 9 & 5 & 0.85 & 10.2 \\
\hline 10 & 5 & 0.55 & 6.6 \\
\hline 11 & 5 & 0.55 & 6.6 \\
\hline 12 & 5 & 0.55 & 6.6 \\
\hline
\end{tabular}

Sumber : Hasil Perhitungan 2021

PAWON: Jurnal Arsitektur, Nomor 02 Volume V, Juli-Desember Tahun 2021, ISSN 2597-7636 
Tabel 11

Rekapitulasi Laju Infiltrasi

\begin{tabular}{ccc} 
No Lokasi & \multicolumn{2}{c}{ Laju Infiltrasi (cm/jam) } \\
& Dengan LRB & Tanpa LRB \\
\hline Titik 1 & 34,8 & \\
\hline Titik 2 & & 6,6 \\
\hline Titik 3 & 58,8 & \\
\hline Titik 4 & & 2,4 \\
\hline Titik 5 & 56,4 & \\
\hline Titik 6 & & 4,2 \\
\hline Rata-rata & $\mathbf{5 0}$ & $\mathbf{4 , 4}$ \\
\hline
\end{tabular}

Sumber : Hasil Perhitungan 2021

\subsection{Analisis Debit dan Jumlah LRB}

Analisis debit air yang masuk pada satu LRB yang berdiameter 4 inch dengan kedalaman $100 \mathrm{~cm}$ dapat dihitung dengan mengkalikan laju infiltrasi dengan luas selimut LRB. Laju infiltrasi rata-rata yang diperoleh dari hasil analisis sebelumnya adalah $50 \mathrm{~cm} / \mathrm{jam}$. Berikut merupakan perhitungan debit LRB.

Debit $_{\text {LRB }}=$ Laju infiltrasi $x$ Luas lubang resapan biopori

Debit $_{\text {LRB }}=50 \mathrm{~cm} \times(3.14 \mathrm{~cm} \times 10 \mathrm{~cm} \times 100 \mathrm{~cm})$

Debit $_{\text {LRB }}=157000 \mathrm{~cm}^{3} / \mathrm{jam}$

$=0.00004361 \mathrm{~m}^{3} / \mathrm{det}$

Berdasarkan hasil analisis hidrologi dan analisis hidrolika di lokasi penelitian terdapat 2 saluran yang tidak memenuhi kapasitas tamping yang ada. Debit limpasan yang diperhitungkan adalah debit tertinggi dari beberapa PUH yaitu periode ulang 10 tahun. Berikut merupakan rumus yang digunakan dalam menghitung jumlah LRB:

Jumlah LRB $=\frac{\text { Qhidrologi }- \text { Qhidrolika }}{\mathrm{Q}_{L R B}}$

Tabel 11

Rekapitulasi Jumlah dan Debit LRB

\begin{tabular}{ccc}
\hline $\begin{array}{c}\text { Tipe } \\
\text { Saluran }\end{array}$ & Jumlah LRB & Debit Total LRB \\
\hline Saluran 1 & 3107 & $0.135511 \mathrm{~m}^{3} / \mathrm{det}$ \\
\hline Saluran 2 & 1273 & $0.05549873 \mathrm{~m}^{3} / \mathrm{det}$ \\
\hline \multicolumn{4}{c}{ Sumber : Hasil Perhitungan 2021}
\end{tabular}

PAWON: Jurnal Arsitektur, Nomor 02 Volume V, Juli-Desember Tahun 2021, ISSN 2597-7636 


\subsection{Hasil Evaluasi Saluran dengan Sistem Ecodrainage}

Berdasarkan hasil evaluasi penampang saluran terdapat 2 saluran yang tidak memenuhi kapasitas, yaitu pada saluran 2 dan saluran 3, maka dengan adanya system ecodrainage yaitu penerapan lubang resapan biopori maka banjir pada kedua saluran tersebut dapat ditanggulangi. Berikut merupakan rekapitulasi debit dengan menerapkan ecodraiange.

Tabel 12

Rekaptulasi Debit dengan Menerpakan Ecodrainage

\begin{tabular}{|c|c|c|c|c|c|}
\hline \multirow[b]{2}{*}{ Saluran } & \multicolumn{2}{|c|}{ Qhidrologi } & \multirow[b]{2}{*}{$\begin{array}{c}\text { Qhidrolika } \\
\text { m }^{3} / \text { det }\end{array}$} & \multirow[b]{2}{*}{$\begin{array}{l}\text { Q LRB } \\
\mathbf{m}^{3} / \text { det }\end{array}$} & \multirow{2}{*}{$\begin{array}{c}\text { Hasil Evaluasi } \\
\text { Qhidrologi < } \\
\text { Qhidrolika+QLRE }\end{array}$} \\
\hline & $\begin{array}{l}\text { Periode } \\
\text { Ulang }\end{array}$ & $\mathrm{m}^{3} / \mathrm{det}$ & & & \\
\hline \multirow{3}{*}{$\begin{array}{l}\text { Saluran } \\
\quad 2\end{array}$} & $Q_{2}$ th & 0,4637 & 0,4127 & 0,13551 & Memenuhi \\
\hline & $Q_{5}$ th & 0,5301 & 0,4127 & 0,13551 & Memenuhi \\
\hline & $Q_{10}$ th & 0,5483 & 0,4127 & 0,13551 & Memenuhi \\
\hline \multirow{3}{*}{$\begin{array}{c}\text { Saluran } \\
\mathbf{3}\end{array}$} & $Q_{2}$ th & 0,2488 & 0,2387 & 0,055499 & Memenuhi \\
\hline & $Q_{5}$ th & 0,2844 & 0,2387 & 0,055499 & Memenuhi \\
\hline & $Q_{10}$ th & 0,2942 & 0,2387 & 0,055499 & Memenuhi \\
\hline
\end{tabular}

Sumber : Hasil Perhitungan, 2021

\section{KESIMPULAN}

1. Debit hidrolika menunjukkan saluran 1 mampu menampung debit sebesar $1.7546 \mathrm{~m}^{3} / \mathrm{s}$, sedangkan pada saluran 2 mampu menampung debit sebesar $0.4127 \mathrm{~m}^{3} / \mathrm{s}$, serta pada saluran 3 memiliki kapasitas tampungan sebesar $0.2387 \mathrm{~m}^{3} / \mathrm{s}$.

2. Penerapan system ecodrainage dengan pembuatan LRB sebanyak 3107 buah di sekitar saluran 2 dan 1273 buah LRB di sekitar saluran 3 dapat disimpulkan mampu menanggulangi banjir pada lokasi penelitian. Hal ini ditunjukkan dengan hasil evaluasi akhir yang menunjukkan semua saluran memenuhi debit banjir rencana. 


\section{DAFTAR PUSTAKA}

Abdeldayem, S, 2005, Agricultural Drainage: Towards an Integrated Approach, Irrigation and Drainage Systems.

Asdak, Chay, 1995, Hidrologi Dan Pengelolaan Daerah Aliran Sungai. Yogyakarta: Gadjah Mada University Press.

H.A. Halim Hasmar, 2002, Drainase Perkotaan. UII Press Yogyakarta.

R, Kamir dkk, 2009, Lubang Resapan Biopori untuk Mitigasi Banjir, Kekeringan dan Perbaikan. Prosiding Seminar Lubang Biopori (LRB) dapat Mengurangi Bahaya banjir di Gedung BPPT2009. Jakarta.

Suripin, 2004, Sistem Drainase Perkotaan yang Berkelanjutan. Andi,Yogyakarta.

Tim Biopori, 2007. Biopori : Teknologi Tepat Guna Ramah Lingkungan, 
